\title{
Preparation and Corrosion Resistance of Biodegradable PDLLA-Mg-1.0Ca-ZnP Composite Material
}

\author{
Meina Huang ${ }^{1,2, a^{*}}$,and Shuiwen Yang ${ }^{3, b}$ \\ ${ }^{1}$ Chongqing Key Laboratory of Manufacturing Equipment Mechanism Design and Control, \\ Chongqing Technology and Business University, Chongqing 400067, China \\ ${ }^{2}$ Chongqing Engineering Research Center for Processing, Story and Transportation of \\ Characterized Agro-Products, Chongqing Technology and Business University, Chongqing \\ 400067, China \\ ${ }^{3}$ Chongqing Solid Waste Management Center, Chongqing Environment Protection Agency \\ 401147, China \\ a* meinahuang1982@163.com b yangshuiwen@126.com
}

Keywords: Preparation; Polymer coating; Corrosion resistance; PDLLA-Mg-1.0Ca-ZnP

\begin{abstract}
Objective: Preparation of the novel material for bone repair. Methods: PDLLA coating method was used. Results: The PDLLA-Mg-1.0Ca-ZnP composite material was prepared by using both PDLLA coating and the phosphate coating (recorded $\mathrm{ZnP}$ ), and the corrosion resistance of PDLLA-Mg-1.0Ca-ZnP were tested. Conclusion: Electrochemical tests showed that PDLLA-AZ31 had higher free corrosion potentials (Ecorr) and lower corrosion currents (Icorr), high impedence in the simulated body fluid (SBF) at $37^{\circ} \mathrm{C}$.
\end{abstract}

\section{Introduction}

Various studies showed that magnesium had nice degradation and mechanical properties, density analogous to natural bones [1]. Currently, there are many studies, which mainly focus on commercial alloys, such as AZ31 and Mg-RE alloys [2-4]. However, it is reported that Al element can cause nerve toxicity and retraining growth to the human body [5]. Moreover, the RE may cause the severe hepatotoxicity [5]. Calcium is one of the most attractive elements due to the fact that it is a major component of human bones and essential in chemical signaling with cells. Moreover, magnesium is necessary for the calcium incorporation into the bone, which might be expected to be beneficial to the bone healing with the co-releasing of $\mathrm{Mg}$ and $\mathrm{Ca}$ ions [6].

However, the introduction of $\mathrm{Ca}$ can decrease the corrosion resistance. Recently, many surface modification techniques such as electrodeposition[7], polymer coating [8], phosphating treatment [9], and microarc oxidation [10], which are used to increase the corrosion resistance of alloy, have been studied. PDLLA was chosen to use as the coating polymer because it was biodegradable and biocompatible, and had been approved to apply in clinical operations by FDA [11].

\section{Materials and Methods}

Preparation of PDLLA-Mg-1.0Ca-ZnP Composite Materials. Firstly, Mg-1.0Ca alloy (1wt. \% $\mathrm{Ca}$ ) was prepared from pure $\mathrm{Mg}(99.98 \%)$ and $\mathrm{Mg}$-Ca alloy $(30 \mathrm{wt} . \% \mathrm{Ca})$ in a crucible under a mixed gas atmosphere of $\mathrm{SF}_{6}$ and $\mathrm{CO}_{2}$. And then $\mathrm{Mg}-1.0 \mathrm{Ca}$ alloy was cut to round plates $(\Phi 12 \mathrm{~mm} \times 2.5 \mathrm{~mm})$. All the specimens were mechanically polished up to 1000 grit and then were electropolished and dried at room temperature.

Secondly, $\mathrm{ZnP}$ coating is formed on $\mathrm{Mg}-1.0 \mathrm{Ca}$ alloy by zinc phosphating in phosphating bath. The optimal contents of chemical compositions of the zinc phosphating and experimental conditions are listed in Table 1[12]. The zinc phosphating Mg-1.0Ca was named Mg-1.0Ca-ZnP.

Thirdly, PDLLA (-(- $\left.\left.\mathrm{CHCH}_{3} \mathrm{COO}\right)_{\mathrm{n}^{-}}\right)$with an average molecular weight of about 50, 000 was bought from Shandong Province. The PDLLA was dissolved in dichloromethane as the 
concentration $3 \mathrm{wt} \%$. PDLLA coating was carried out by soaking $\mathrm{Mg}-1.0 \mathrm{Ca}$ into PDLLA solution at room temperature. And then all samples were dried at $40^{\circ} \mathrm{C}$ for $72 \mathrm{~h}$. Surface morphologies of magnesium substrate and magnesium compound were observed with SEM.

Table 1 Compositions of the phosphating bath and experimental conditions

\begin{tabular}{|c|c|c|c|c|c|}
\hline & Degreasing & $\begin{array}{l}\text { Ultrasonic } \\
\text { derusting }\end{array}$ & $\begin{array}{c}\text { Surface } \\
\text { conditioning }\end{array}$ & \multicolumn{2}{|c|}{ Phosphating/L } \\
\hline \multirow{8}{*}{ Compositions } & \multirow{8}{*}{$\begin{array}{l}\mathrm{NaOH} \\
1.5 \mathrm{wt} \%\end{array}$} & \multirow{8}{*}{$\begin{array}{c}\mathrm{H}_{3} \mathrm{PO}_{4}: \mathrm{HNO}_{3} \\
\quad=300: 1\end{array}$} & \multirow{8}{*}{$\begin{array}{c}\text { 200-250ml/L } \\
\mathrm{HF}\end{array}$} & $\begin{array}{l}\mathrm{H}_{3} \mathrm{PO}_{4} \\
(85 w t . \%)\end{array}$ & $30 \mathrm{ml}$ \\
\hline & & & & $\mathrm{ZnO}$ & $6.8 \mathrm{~g}$ \\
\hline & & & & $\mathrm{NaF}$ & 1.8 \\
\hline & & & & NaNO3 & 2.8 \\
\hline & & & & $\mathrm{NaNO} 2$ & 1.2 \\
\hline & & & & Citric acid & 2.8 \\
\hline & & & & MEA & 1.2 \\
\hline & & & & SDS & 0.15 \\
\hline \multirow{2}{*}{ Conditions } & $1 \mathrm{~min}$ & $3-5 s$ & $15 \mathrm{~min}$ & \multicolumn{2}{|c|}{$10 \mathrm{~min}$} \\
\hline & $50-60^{\circ} \mathrm{C}$ & $25^{\circ} \mathrm{C}$ & $25^{\circ} \mathrm{C}$ & \multicolumn{2}{|c|}{$45^{\circ} \mathrm{C}$} \\
\hline
\end{tabular}

Electrochemical test. Electrochemical test was performed to evaluate the corrosion resistance of $\mathrm{Mg}-1.0 \mathrm{Ca}$ and PDLLA-Mg-1.0Ca-ZnP. The potentiodynamic polarization and electrochemical impedance spectroscopy (EIS) were tested. The electrochemical test was conducted with a three-electrode system in $150 \mathrm{ml} \mathrm{SBF}$ at $37^{\circ} \mathrm{C}$. A saturated calomel electrode and platinum mesh were used as the reference and counter electrode, respectively. The polarization curves were measured at a scan rate of $1 \mathrm{mVs}^{-1}$. The free corrosion potential $\left(E_{\text {corr }}\right)$ and current $\left(I_{\text {corr }}\right)$ for each specimen were also tested. In the potentiodynamic polarization test, a scanning rate of $2 \mathrm{mVs}^{-1}$ was applied.

\section{Results and Discussion}

Electrochemical behavior. Representative polarization curves of $\mathrm{Mg}-1.0 \mathrm{Ca}$ and PDLLA-Mg-1.0Ca-ZnP are depicted in Fig. 1. The untreated $\mathrm{Mg}-1.0 \mathrm{Ca}$ alloy has a negative corrosion potential in SBF of about $-1806 \mathrm{mV}$. The corrosion potential ( $\mathrm{E}_{\text {corr }}$ of PDLLA-Mg-1.0Ca-ZnP is much more positive, shifting to about $1538 \mathrm{mV}$. The corrosion current density $\left(\mathrm{I}_{\text {corr }}\right)$ of PDLLA-Mg-1.0Ca-ZnP $\left(1.068 \mathrm{e}-008 \mathrm{Acm}^{-2}\right)$ is about four orders of magnitude lower than that of the untreated sample $\left(3.103 \mathrm{e}-004 \mathrm{Acm}^{-2}\right)$, indicating much lower corrosion rates for the PDLLA coated sample in SBF compared to the Mg-1.0Ca alloy.

The corrosion potential $\left(\mathrm{E}_{\text {corr }}\right)$ reflected the combined outcome of all the electrochemical reactions taking place at the electrode /solution interface. The variation in the corrosion potential with immersion time can be employed to study what goes on at the electrode/solution interface. The typical $\mathrm{E}_{\text {corr }} \mathrm{t}$ curves determined from the $\mathrm{Mg}-1.0 \mathrm{Ca}$ and PDLLA-Mg-1.0Ca-ZnP are shown in Fig.1. It can be seen that the $\mathrm{E}_{\text {corr }}$ of the PDLLA-Mg-1.0Ca-ZnP sample is -1583 , which is much more positive than that of $\mathrm{Mg}-1.0 \mathrm{Ca}$. Therefore, comparing the curves of $\mathrm{Mg}-1.0 \mathrm{Ca}$ and PDLLA-Mg-1.0Ca-ZnP, we can find that, at the beginning of test, the potential of them all have an increase quickly, however, the curve of PDLLA-Mg-1.0Ca-ZnP moves to smooth and steady state quickly, while the curve of $\mathrm{Mg}-1.0 \mathrm{Ca}$ increases continually till the last. The results can be attributed to the chemical dissolution. As it is well-known that when the magnesium-based alloy is put into water medium, magnesium reacts with water to product the main byproduct $\operatorname{Mg}(\mathrm{OH})_{2}$, which leads to the precipitation of the corrosion products as magnesium hydroxide, magnesium phosphate, and magnesium carbonates[13]. However, when magnesium alloy was coated, the coating PDLLA protected the magnesium alloy from corrosion potential increasing gradually with immersion time. 


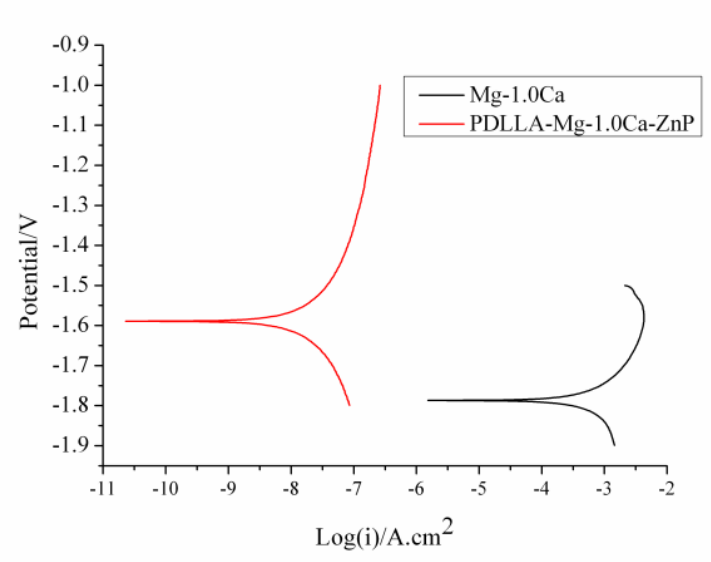

Figure 1. Potentiodynamic polarization curves of the PDLLA-Mg-1.0Ca-Z in SBF

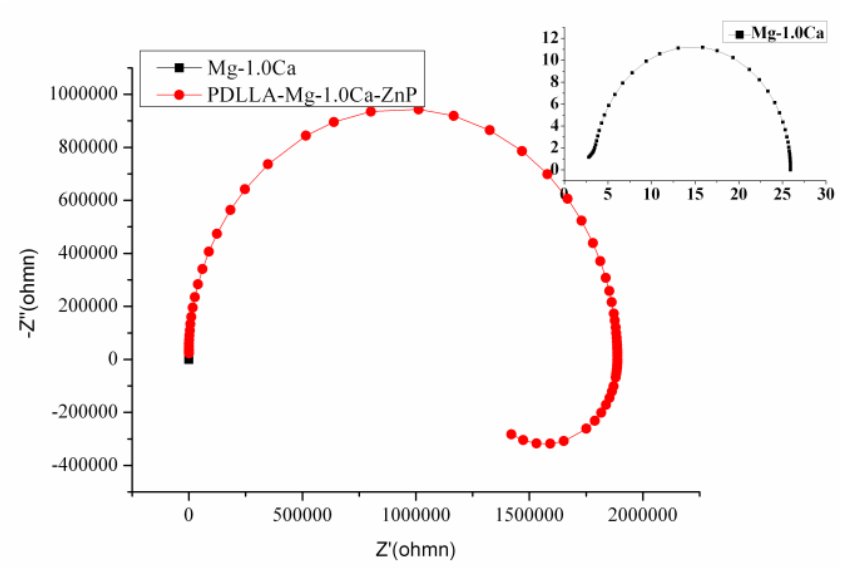

Figure 2. Representative EIS spectra of the $\mathrm{Mg}-1.0 \mathrm{Ca}$ and PDLLA-Mg-1.0Ca-ZnP and Mg-1.0Ca in SBF

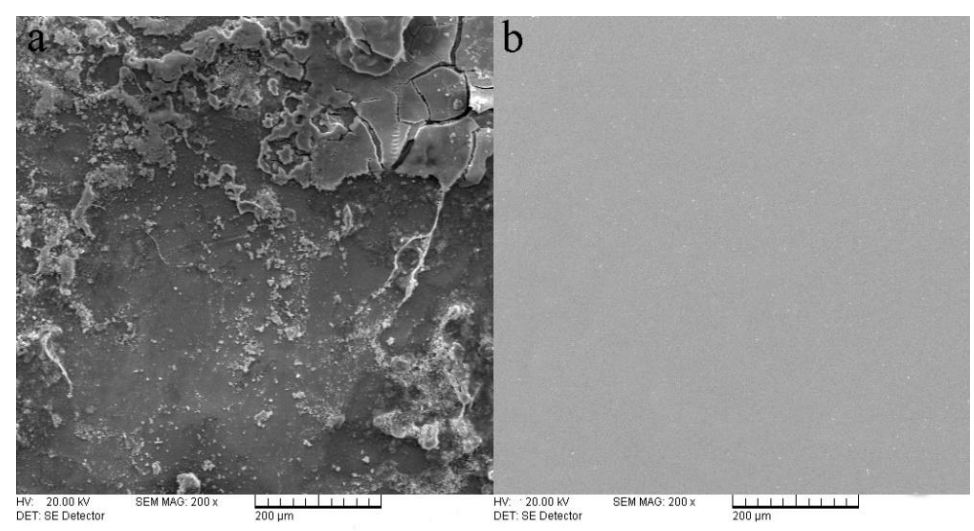

Figure 3. The SEM of Mg-1.0Ca (a) and PDLLA-Mg-1.0Ca-ZnP (b) after EIS test ( $\times 200)$

EIS is a powerful technique to study the corrosion of uncoated magnesium alloy and coated magnesium alloy. It can evaluate the corrosion properties of all samples quantitatively, which is difficult to evaluate by conventional corrosion evaluation method. By appropriate interpretation of EIS data in conjunction with an EC, the detailed information on the corrosion process at the electrolyte/electrode interface can be provided. This technique is more effective to study the localized corrosion via small pores [14]. The representative EIS curves obtained from $\mathrm{Mg}-1.0 \mathrm{Ca}$ alloy and PDLLA-Mg-1.0Ca-ZnP alloy as function of immersion time in SBF are shown in Fig. 2. The EIS curve can be divided into three stages: low frequencies, medium frequencies and high frequencies. Right from the beginning of immersion, a capacitive loop at medium frequencies, and a Warburg loop at low frequencies, this is aroused by ionic migration impedance. The high frequency behavior of EIS is associated with electrolyte impedance including water and salt. The medium-high frequency of EIS is associated with the interface, which shows passivation coating impedance and charge transfer impedance in interface, therefore the properties of the coatings and their changes can be determined at the medium-high frequencies [14]. Comparing the EIS of $\mathrm{Mg}-1.0 \mathrm{Ca}$ with EIS of PDLLA-Mg-1.0Ca-ZnP in Fig. 2, we can find that the impedance increased from 30 to $1.5 \mathrm{e} 6$. Moreover, from the results of Fig. 3, we can find that the PDLLA-Mg-1.0Ca-ZnP shows the smooth intact surface morphology, while Mg-1.0Ca shows severe corrosion. All results showed that PDLLA coating played an obvious role in improving the corrosion resistance of $\mathrm{Mg}$-1.0Ca alloy.

Considering the nice corrosion resistance of PDLLA-Mg-1.0Ca-ZnP, it was used directly for the following cell experiments.

\section{Acknowledgements}

The present work was supported by the National Natural Science Foundation of Chongqing 
(CSTC2013jcyjA50019), and the National Natural Science Foundation of Chongqing Teaching Co mmittee(KJ1500616), and the Doctoral research start-up funding of Chongqing Technology and Business University(670101098)

\section{References}

[1] A. Tahmasebifar, S. M. Kayhan, Z. Evis,A. Tezcaner, H. Cinici and M. Koc: Jounal of Alloys and compounds, Vol. 687 (2016) No. 5, p.906.

[2] S. N. Dezfuli, Z. G. Huan, A. Mol, S. Leeflang, J. Chang and J. Zhou: Materials Science and Engineering : C, Vol. 79 (2017) No. 1, p. 647.

[3] S. Jafari and R.K. Singh Raman: Materials Science and Engineering : C, Vol. 78 (2017) No. 1, p. 278.

[4] C.Y. Zhang, R. C. Zeng, R. S. Chen , C. L. Liu and J. C. Gao : Trans Nonferrous Met Soc China, Vol. 20 (2010) No. 1, p. 655.

[5] L. B. Feng, Y. L. Zhu, J. Wang and X. T. Shi: Applied Surface Science, Vol. 422 (2017) No. 15, p. 278.

[6] A. P. M. Saad, R. A. A. Rahim, M. N. Harun, H. Basri, et al: Materials \& Design, Vol. 122 (2017) No. 15, p. 268.

[7] R. G. Guan, I. Johnso, T. Cui, T. Zhao, Z. Y. Zhao, X. Li and H. Liu: Journanl of Biomedical Materials Research Part A, Vol. 100A(2012), p. 999.

[8] Y. Chen, Y. Song, S. Zhang, J. Li, C. Zhao and X. Zhang: Biomedical Materials, Vol. 6( 2011) No. 2, p. 5005.

[9] L. Xu, F. S. Pan, G. Yu, L. Yang, E. Zhang and K. Yang: Biomaterials, Vol. 30(2009) No. 8, p.1512.

[10] X. Gu, N. Li, W. Zhou, Y. Zheng, X. Zhao, Q. Cai and L. Ruan: Acta Biomaterials, Vol. 7(2011)No. 4, p. 1880.

[11] Y. L. Wang, M. N. Huang, Y. F. Luo, Y. G. Li: Polymer Degradation and Stability, Vol. 95 (2010), p. 549.

[12] R. C. Zeng, F. Zhang, Z. D. Lan, H. Z. Cui and E. H. Han: Corrosion Science, Vol. 88 (2014), p. 452.

[13] S. R. Kiahosseini, A. Afshar, M. M. Larijani and M. Yousefpour: Applied surface Science, Vol. 401(2017), p. 172.

[14] Xin Y, Jiang J, Huo K, Tang G, Tian X, Chu PK. Corrosion resistance and cytocompatibility of biodegradable surgical magnesium alloy coated with hydrogenated amorphous silicon. J Biomed Mater Res Part A 2009; 89: 717-726. 